\title{
Chiropractic Treatments May Cause Stokes
}

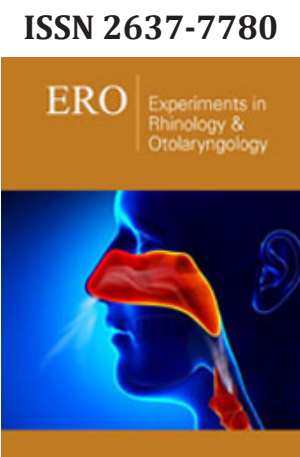

*Corresponding author: Cusack PTE, Independent Researcher, Canada

Submission: 眏 June 19, 2019

Published: 祭June 29, 2019

Volume 3 - Issue 1

How to cite this article: Cusack $P$. Chiropractic Treatments May Cause Stokes. Exp Rhinol Otolaryngol 3(1). ERO.000555.2019.

DOI: 10.31031/ERO.2019.03.000555

Copyright@ Cusack PTE, This article is distributed under the terms of the Creative Commons Attrib u t i o n 4.0 International License, which permits unrestricted use and redistribution provided that the original author and source are credited.
Cusack PTE*

Independent Researcher, Canada

\section{Opinion}

As someone who has suffered from back and neck pain for years, and after many treatments from qualified Chiropractors, I believe such treatments to the neck is potentially very harmful for the patient. It may lead to a stoke. The Chiropractic treatments produce a feeling of relief certainly, but that relief is temporary. Eventually, the patient may start to seek that relief by treating him/herself. There is potential for a stoke since the arteries in the neck are adversely affected. I don't know if surgery to the vertebrae would help, but chiropractic treatment only buys so much time.

There is a debate between doctors who oversees a chiropractic patient. Does the primary physician have the professional responsibility, or can the Chiropractor take control away from the General Practitioner? of course, the relief of suffering must be balanced with the risks involved. It is my opinion that the chiropractor treatments lead to a potential situation where the patient suffers a stoke. One could argue that the Chiropractor should be the only one who does the treatments. But the reality is the patient will seek out that relief on his or her own. Do no harm is the mantra here. Further discussions and investigations are warranted. 